Didaché: Journal of Christian Education

Vol. 2, No. 1 (2021): 87-98

e-ISSN: $2722-8584$

Published by: Sekolah Tinggi Teologi Simpson Ungaran

DOI: $10.46445 /$ djce.v2i1.359

\title{
Peran Gembala Jemaat dalam Pengajaran Agama Kristen terhadap Keterlibatan Warga Jemaat dalam Pelayanan
}

\author{
Rotua J.R. Hutagalung, Romi Lie \\ Sekolah Tinggi Teologi Jaffray Jakarta \\ Email: hutagalungrotua30@gmail.com, romilie0982@gmail.com
}

\begin{abstract}
Lack of church involvement in every church activity (service), because the congregation does not get guidance, direction, and teaching. If Christian religious teaching is taught properly and healthily, the congregation will be strong (survive), experience a change in thinking (cognitive), attitude (affective), and willing to be involved (psychomotor) in church activities. That is why, if the congregation has received formation, teaching properly and healthily, they will take root, grow, and bear fruit (Colossians 3:17). The method presented during the study was to use quantitative methods, namely distributing questionnaires to members of the Church of Christ Rahmani Indonesia, Sola Gratia Church, Ruko Permata Ujung Menteng. As a result, as a pastor, the task is not only to shepherd but also to be responsible for the spirituality of the church in providing teaching, formation, direction, and training to church members.
\end{abstract}

Keywords: Teaching, Congregation, Service, Pastor

\begin{abstract}
Abstrak
Kurangnya keterlibatan jemaat di dalam setiap kegiatan gereja (pelayanan), karena jemaat tidak mendapatkan bimbingan, arahan, dan pengajaran. Apabila pengajaran Agama Kristen diajarkan secara benar dan sehat maka jemaat akan kuat (survive), mengalami suatu perubahan di dalam berpikir (kognitif), bersikap (afektif), serta mau untuk terlibat (psikomotor) di dalam kegiatan-kegiatan gereja. Itu sebabnya, jika jemaat sudah mendapatkan pembinaan, pengajaran secara benar dan sehat maka mereka akan berakar, bertumbuh, dan berbuah (Kolose 3:17). Metode yang disajikan selama penelitian adalah menggunakan metode kuantitatif yaitu penyebaran angket kepada para anggota jemaat di Gereja Kristus Rahmani Indonesia Jemaat Sola Gratia, Ruko Permata Ujung Menteng. Hasilnya sebagai seorang gembala tugasnya tidak saja menggembalakan tetapi ia juga bertanggung jawab terhadap kerohanian jemaat di dalam memberikan pengajaran, pembinaan, pengarahan, dan pelatihan kepada warga jemaat.
\end{abstract}

Kata kunci: Pengajaran, Warga Jemaat, Pelayanan, Gembala Jemaat 


\section{Pendahuluan}

Amanat Agung Tuhan Yesus di dalam Matius 28:19-20 menjadi promotor atau pengerak setiap umat Tuhan untuk menjadikan semua bangsa murid (Darmawan, 2019). Salah satu aspek menjadi murid adalah dengan kata "ajarlah mereka melakukan segala sesuatu...", kata ajar' dalam bahasa Yunani $\delta \imath \delta a \sigma \kappa \omega$ (didasko) yang berarti suatu pekerjaan atau aktifitas mengajar yang dilakukan secara terus menerus (BibleWorks, n.d.; Tanduklangi, 2020). Hal ini jelas bahwa Yesus menginginkan setiap warga gereja yang sudah mendengar pengajaran firman Tuhan dapat mentaati dan mempraktekkan firman Tuhan di dalam kehidupannya.

Istilah pendidikan dalam bahasa Inggris adalah education, kata ini berasal dari bahasa Latin educere berarti membimbing keluar (Nuhamara, 2007). Secara etimologinya pendidikan adalah 'paedagogie' yang diterjemahkan membimbing (Ahmadi, 1991). Berdasarkan pengertian di atas, Pendidikan Agama Kristen adalah usaha mendewasakan manusia melalui upaya pengajaran dan pelatihan serta cara mendidik atau membimbing seseorang untuk mengalami suatu perubahan kognitif, afektif dan psikomotor sehingga terbentuklah manusia mandiri dan bertanggung jawab dihadapan Tuhan.

Pengajaran agama dalam Perjanjian Lama sebenarnya menyiapkan umat Israel untuk menyambut kedatangan Mesias, dan karya tersebut dinyatakan di dalam pengajaran tentang Hukum-hukum Allah dan kurban. Pengajaran agama Kristen dimulai sejak terpanggilnya Abraham sampai kepada janji Allah kepada Abraham bahwa keturunannya akan menjadi suatu bangsa yang besar (Kej.12:23), dan pusat pendidikan agama saat itu terletak pada keluarga, seperti di dalam keluarga Abraham, Ishak, dan Yakub, karena merekalah yang bertanggung jawab dalam pendidikan agama dan mengajarkannya kepada anak-anaknya (Ul. 5:16; 6:4-9), (Mary, 2020). Pengajaran agama dalam Perjanjian Lama berpusat pada Hukum Allah dan kurban melalui sistem Imamat (Kristianto, 2006).

Pengajaran agama di Perjanjian Baru tidak terlepas dari pendidikan atau pengajaran agama di dalam Perjanjian Lama yaitu karya penyelamatan manusia oleh Allah. Karya penyelamatan manusia dalam Perjanjian Baru dinyatakan dalam pribadi Kristus, "Akulah jalan dan kebenaran dan hidup. Tidak ada seorang pun yang datang kepada Bapa, kalau tidak melalui Aku" (Yoh.14:6) (Kristianto, 2006; Susanti, 2017). Tujuan Yesus mengajar adalah pertama, agar manusia dibenarkan di hadapan Allah dan menerima Tuhan sebagai Juruselamatnya; kedua, melayani tiap-tiap manusia yang datang pada-Nya, mengenal setiap pribadi-pribadi yang diajar-Nya dan ketiga, Yesus mengenal setiap permasalahan-permasalahan yang dihadapi oleh murid-murid-Nya (Homrighausen \& Enklaar, 1999). 
Atas dasar di atas, dapat dikatakan bahwa pengajaran agama dalam gereja sangat penting. Tugas gereja adalah memberitakan firman Tuhan dengan khotbah (Camerling, Lauled, \& Eunike, 2020; Oei, 2017; Ronda, 2016) dan dengan melayani sakramen-sakramen Perjamuan Kudus dan Baptisan (Sumiyati \& Mendrofa, 2021), gereja terpanggil untuk menyampaikan firman Tuhan melalui pekabaran Injil (Salurante, 2021; Tomatala, 2020), gereja terpanggil untuk menggembalakan kawanan domba Tuhan dengan perkunjungan rumah tangga (Widiyanto \& Susanto, 2020), dan gereja pun wajib menunjukkan kasih Kristus kepada banyak orang (Homrighausen \& Enklaar, 1999).

Esensi gereja bukanlah pada gedungnya atau suatu organisasi, melainkan pada pribadi-pribadi yang telah percaya kepada Yesus Kristus. Di dalam Perjanjian Lama pengertian gereja memakai dua istilah yaitu qahal atau kahal artinya memanggil, dan edhah artinya memilih atau menunjuk atau bertemu bersama-sama di satu tempat yang telah ditunjuk (Berkhof, 2008). Kata Sinagoge dipakai dalam Septuaginta untuk edhah. Akan tetapi dalam Perjanjian Lama bagian akhir qahal diterjemahkan menjadi ekklesia (Berkhof, 2008). Dalam Perjanjian Baru dua kata yang diambil dari Septuaginta, ekklesia yang berasal dari kata -ek dan kaleo, artinya memanggil keluar yang berarti bahwa gereja terdiri dari orang-orang pilihan yang dipanggil keluar dari masyarakat (Berkhof, 2008). Ekklesia dimaknai sebagai suatu perkumpulan orang-orang (yang dipanggil), dan Tuhan sendiri yang memanggil mereka (Berkhof, 2008). Dalam Matius 16:18, Tuhan Yesus menujuk murid-murid-Nya sebagai gereja, hal ini dapat dilihat dari pemakaian kata ekklesia.

Gereja sebagai tubuh Kristus hanya dapat dipahami berdasarkan iman yang tumbuh oleh kuasa Roh Kudus. Melalui kehadiran Roh Kudus (band. Kis.2) Allah bekerja mempersatukan jemaat-jemaat melalui umat pilihan-Nya. Adanya jemaat sebagai tubuh Kristus di dunia ini adalah karena pekerjaan Roh Kudus yang memimpin dan menolong anggota jemaat (Rm. 8:15-16,26) (Berkhof, 2008). Berdasarkan dari beberapa pandangan di atas dapat disimpulkan bahwa gereja bukanlah suatu bangunan, tetapi gereja merupakan suatu perkumpulan orangorang yang telah dipanggil dan dipilih oleh Tuhan dari tempat kegelapan yaitu dosa ke dalam terang yang ajaib menjadi anak Allah (1 Pet. 2:9-10).

Tuhan mengaruniakan kepada gereja rasul-rasul, nabi-nabi, pemberitapemberita Injil, gembala-gembala, dan pengajar-pengajar untuk 'memperlengkapi orang-orang kudus bagi pekerjaan pelayanan' (Ef. 4:11-15). Yesus juga telah memberikan Amanat Agung-Nya, yang berisi perintah bukan saja untuk menjadikan orang-orang murid dan membaptiskan mereka tetapi juga mengajarkan mereka 'melakukan segala sesuatu' yang telah diperintahkan-Nya (Mat. 28:1920) (Darmawan, 2019). Oleh karena itu, tidak dapat disangkal lagi bahwa gereja 
harus menjalankan program pendidikan dan pelatihan bagi anggota-anggota jemaatnya, baik muda mau pun tua. Gereja harus mengajarkan kebenaran-kebenaran Tuhan kepada jemaatnya. Gereja harus dengan setia mengajarkan ajaran para rasul (Theissen, 2003).

Dasar pelayanan dalam Perjanjian Lama ketika TUHAN berfirman kepada Abraham untuk pergi dari negeri dan sanak saudaranya (Kejadian 12:1-3), hal ini menunjukkan atau menjelaskan bahwa tujuan TUHAN memanggil Abraham adalah agar ia memberitakan kebaikan-kebaikan Allah sehingga semua orang memperoleh berkat. Di dalam Perjanjian Baru, Yesus memberikan teladan diri dalam melayani, seperti terdapat di Matius 20:25-28, Yesus sebagai Anak Manusia datang bukan untuk dilayani, melainkan untuk melayani dan memberikan nayawa-Nya bagi banyak orang. Yesus sebagai Kepala Gereja, Ia menetapkan dan memberikan otoritas Ilahi kepada pejabat gereja sehingga mereka dapat berbicara dan bertindak dalam nama-Nya (Mat. 10:1). Kendati pun Kristus memberikan kuasa kepada gereja, Ia juga menghendaki agar pelaksanaan dalam pelayanan dapat dilakukan oleh orang-orang tertentu secara khusus, yaitu: Pejabat gereja yang dikategorikan sebagai Pejabat Luar Biasa dan Biasa. Pejabat Luar Biasa antar lain seperti: rasul, nabi, pemberita Injil, dan Pejabat Biasa, antara lain seperti: tua-tua, guru, diaken (Berkhof, 2008). Demikian halnya di dalam gereja, Ia pun telah menetapkan setiap masing-masing pelayan menjadi penginjil, pengajar, gembala, sehingga melalui jabatan-jabatan tersebut mereka dapat membina, membimbing, dan memperlengkapi warga gereja-Nya untuk terlibat dalam pelayanan.

Bagian pendidikan atau pengajaran agama Kristen yang dapat diterapkan di dalam suatu pelayanan gereja adalah pendidikan anak melalui Sekolah Minggu, Katekisasi, Khotbah, Pembinaan, Penelahaan Alkitab, serta keterlibatan dalam basis-basis pelayanan sosial, misalnya PAK dalam keluarga, atau kelompokkelompok persekutuan dalam jemaat (Hadinoto, 1993; Nuh, Darmawan, \& Sujoko, 2019; Riniwati, 2020; Tuai, 2020). Jika jemaat memperoleh pendidikan atau pengajaran agama Kristen secara benar maka mereka memiliki akar yang sangat kuat dan buahnya dapat dinikmati oleh orang-orang di sekitarnya.

Dari paparan pentingnya pendidikan di atas, jika gereja tidak memberitakan dan mengajarkan firman Tuhan kepada jemaat-Nya secara benar dan sehat, mereka tidak akan memiliki suatu pemahaman yang benar tentang Kebenaran firman Tuhan. Karena gereja dipandang sebagai alat anugerah yang besar, di mana Kristus adalah Kepala Gereja dan jemaat sebagai tubuh rohaniahNya maka gereja pun terpanggil untuk memberitakan Injil, gereja mempunyai tanggung jawab untuk mengembalakan kawanan domba-Nya, karena gereja adalah kumpulan orang percaya maka jemaat pun dapat mengaplikasikan kasih 
Kristus kepada banyak orang khususnya kepada sesama jemaat dan di lingkungannya (Harmadi \& Diana, 2020; Sagala, 2020; Tanhidy, Daliman, Suparti, \& Siswanto, 2021; Widiyanto \& Susanto, 2020).

Melalui tulisan ini akan diuraikan tentang bagaimana seharusnya peran gembala jemaat sebagai seorang pelayan Tuhan yang memiliki tugas dan tanggung jawab dalam memberikan atau melakukan pengajaran agama Kristen kepada warga jemaat, guna mendorong atau melibatkan (keterlibatan) warga jemaat dalam pelayanan gerejawi.

\section{Metode}

Metode yang digunakan dalam penelitian ini adalah metode kuantitatif. Menurut Zaluchu (2020) metode kuantitatif adalah pendekatan yang lebih menekankan kepada aspek behavioristic dan empiris dari fenomena-fenomena di lapangan atau berdasarkan tingkah laku di lapangan, yang kemudian dijadikan patokan penelitian yaitu penyebaran angket kepada para anggota jemaat. Tempat penelitian di Gereja Kristus Rahmani Indonesia Jemaat Sola Gratia, Ruko Permata Ujung Menteng. Sumber data adalah pengurus gereja dan warga gereja (orang tua, remaja atau pemuda). Penelitian ini dilaksanakan dalam bentuk survei dan data dianalisis secara kuantitatif, kemudian disajikan secara deskriptif disertai tabel.

\section{Hasil}

Berikut adalah hasil penyebaran angket yang dilakukan oleh peneliti kepada dua puluh dua responden (dalam hal ini adalah jemaat), maka dapat dilihat hasilnya sebagai berikut:

Gambar 1. Hasil Penyebaran Angket

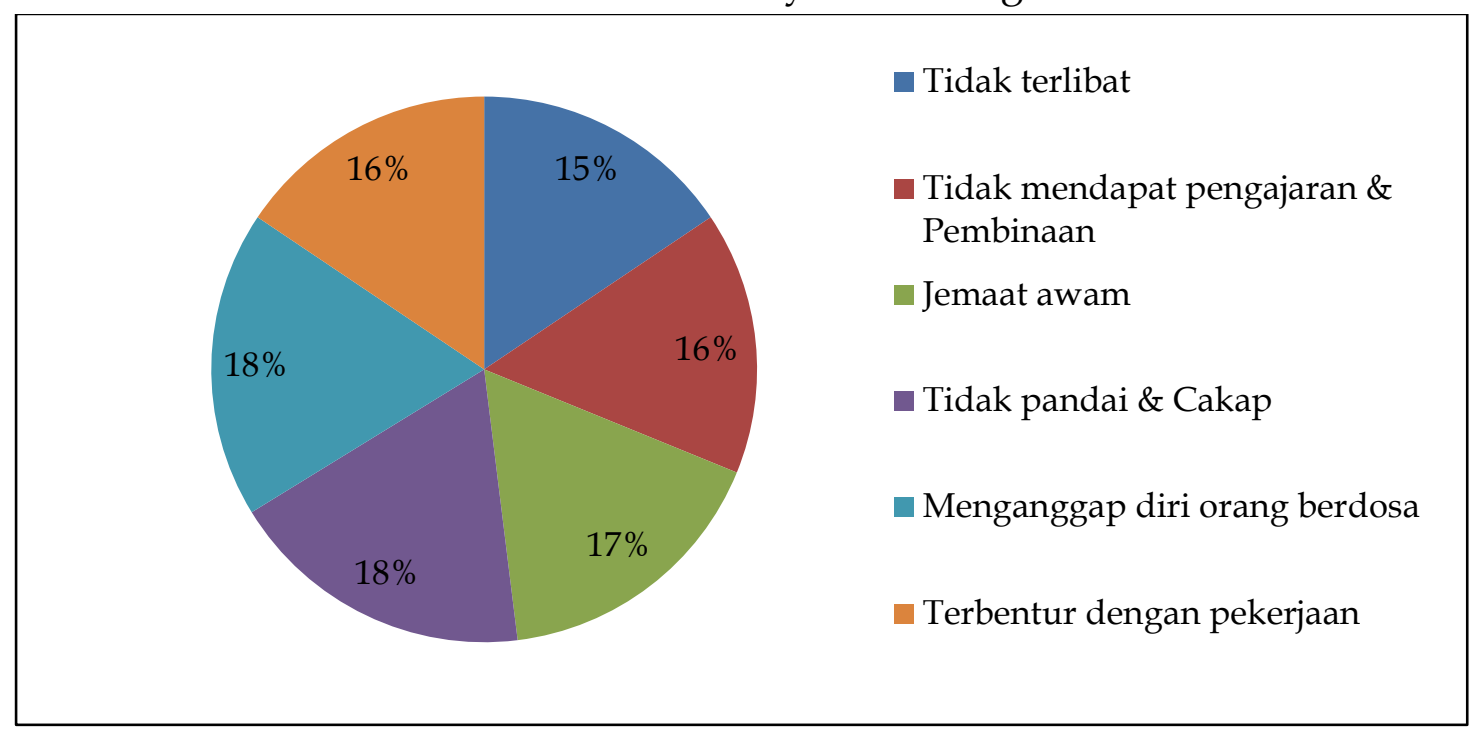

R.J.R. Hutagalung \& R. Lie, Peran Gembala Jemaat dalam Pengajaran Agama Kristen.... 91 
Jika melihat hasil pengelompokkan penelitian di atas, dalam dua puluh dua pertanyaan maka dapat dijelaskan, sebagai berikut: Pertama, sebagian besar kendala yang dihadapi jemaat (responden) adalah tidak adanya keterlibatan jemaat di dalam pelayanan gerejawi 54,5\%; Kedua, tidak mendapatkan pengajaran, pembinaan, dan pengarahan dari seorang gembala secara benar dan sehat $54,5 \%$; Ketiga, tidak memiliki latar belakang teologi 59\%; Keempat, tidak pandai dan cakap dalam menyampaikan firman Tuhan 63,6\%; Kelima, jemaat menganggap bahwa dirinya adalah orang berdosa $63,6 \%$; Keenam, terbentur dengan pekerjaan $54,5 \%$.

\section{Pembahasan}

Atas keenam dasar yang disebutkan dalam bagian hasil maka dapat dilihat adanya suatu ketegasan bahwa tugas tanggung jawab seorang gembala sidang tidak hanya mengembalakan dan memberitakan Injil saja. Gembala juga berperan mendidik, mengajar jemaat secara efektif, kreatif, inovatif dan dinamis serta melaksanakan pembelajaran secara aktif, kreatif, efektif dan menyenangkan. Hal ini sejalan dengan penelitian Tafonao (2018) yang meneliti peran gembala dan paparan Selan (2006) tentang tugas gembala. Inovasi pelayanan yang dilakukan misalnya dalam sekolah minggu seperti dalam temuan Darmawan dan Priskila (2020), dan Darmawan dan Kristanti (2020). Dengan pendidikan seperti ini, pertumbuhan rohani jemaat dapat terjadi (Telaumbanua, 2019).

Peran gembala sidang sebagai pendidik dalam proses pembelajaran Pendidikan Agama Kristen kepada jemaat akan memengaruhi rohani jemaat terhadap pelajaran (firman Tuhan) yang diajarkan. Jika gembala sidang sebagai pendidik dalam pembelajaran mampu berperan baik, misalnya selalu memersiapkan materi yang akan diberikan, mampu menciptakan suasana yang sehat di dalam kelas persekutuan dan selalu memantau pekerjaan dan tugas yang diberikan kepada jemaat serta mampu memotivasi jemaat untuk membaca Alkitab, berdoa dan bersekutu, maka hal itu dapat menumbuhkan kerohanian jemaat (Tafonao, 2018; Telaumbanua, 2019).

Pengajaran yang disampaikan kepada jemaat atau orang lain yang sedang diajar tidak hanya dengan satu pola dan bentuk, tetapi dalam berbagai pola yang tentunya disesuaikan dengan konteks orang-orang atau anggota jemaat (Kosta \& Djadi, 2011). Gereja dapat mengalami pertumbuhan yang sehat dan benar, karena salah satu faktor penting yang menunjang adalah pengajaran yang sehat dan benar. Untuk itu, jemaat perlu diajar kebenaran firman Tuhan melalui Penelaahan Alkitab (PA), adapun tujuan PA adalah supaya setiap peserta: 1) Mengenal Tuhan Yesus dan menerima keselamatan-Nya (Rm. 10:9); 2) Mengerti kehendak Tuhan dalam hidupnya (Rm. 12:2); 3) Mendapat pedoman hidup (II Tim. 3:17); 4) Sanggup menyampaikan Firman Allah yang dipelajarinya kepada orang 
lain (II Tim. 2:2); 5) Menjadikan seorang Kristen yang kuat; 6) Memberitahu bagaimana menyucikan diri dari dosa; 7) Memberi sukacita; 8) Membimbing dalam melakukan keputusan-keputusan dalam hidup kekristenan, dapat menyatakan iman. Akhirnya mengalami pertumbuhan di dalam Tuhan (Navigator, 1996). Apabila kesemua hal tersebut dapat dilakukan oleh jemaat di bawah pengajaran seorang gembala maka mereka akan memiliki pandangan dan pemahaman yang benar terhadap pelayanan sehingga mereka mulai siap untuk terjun di dalam pelayanan gereja.

Berdasarkan hasil tabel penelitian di atas maka 86,3\% jemaat mengakui dan menyatakan bahwa tugas tanggung jawab seorang gembala adalah memberikan pengajaran yang benar dan sehat, dan ini terbukti terhadap pandangan Borong, mengatakan bahwa tugas pengajaran kepada warga jemaat merupakan salah satu tugas pendeta (Borrong, 2016). Itu berarti bahwa pendeta diberikan untuk mengajar, melatih, dan menyempurnakan orang percaya menjadi murid Kristus yang dewasa (Borrong, 2016). Karena salah satu tujuan Yesus mengajar adalah pertama, agar manusia dibenarkan dihadapan Allah dan menerima Tuhan sebagai Juruselamatnya. Kedua, melayani tiap-tiap manusia yang datang padaNya, mengenal setiap pribadi-pribadi yang diajar-Nya. Jadi, bila dikaitkan di dalam kehidupan berjemaat maka mereka yang sudah menerima Kristus Yesus dan diselamatkan maka mereka harus menjadi pelayan yang siap melayani Tuhan. Berdasarkan pengajaran, pembinaan dan pengarahan yang diberikan gembala kepada jemaat maka 100\% jemaat memahami doktrin keselamatan, $100 \%$ jemaat sudah mulai hidup untuk berbagi kepada sesama, 100\% jemaat sudah memiliki kepekaan untuk memberi, 100\% jemaat sudah berani untuk berdoa, 100\% jemaat sudah mengerti akan dosa, karena mereka sudah memahami akan semua pengajaran yang disampaikan oleh seorang gembala maka 100\% jemaat sudah mulai memiliki paradigma atau pandangan yang benar dan sehat terhadap ajaran firman Tuhan, dan 100\% mereka sudah mulai terlibat di dalam pelayanan gereja, seperti yang diungkapkan oleh Jones Akal tentang definisi pelayanan, bahwa jemaat yang sudah terlibat di dalam pelayanan gereja adalah mereka sudah merasakan kebaikkan Allah di dalam hidupnya dan bagaimana Allah melayani dirinya secara pribadi, dan sudah memahami dan mengerti arti sebuah panggilan pelayanan dan memahami semua pengajaran agama Kristen, sementara jemaat yang tidak teribat di dalam pelayanan dikarenakan mereka tidak memahami secara benar arti panggilan pelayanan di dalam kehidupannya (Akal, 2002). Karena itu pengajaran agama Kristen harus ada untuk menunjang 
pertumbuhan jemaat yang semakin banyak mau terlibat di dalam pelayanan gerejawi. Gereja yang vital dan berkembang adalah gereja yang digembalakan oleh seorang shepherd-teacher (gembala-guru) yang memandang dan memperlakukan tugas pengembalaannya sebagai tugas didaktik dan pedagogik, mengajar dan mendidik orang percaya dalam iman (Dawa, 2020).

Demikian halnya yang dikatakan oleh Selan (2006) mengatakan bahwa tugas pendidikan dalam jemaat adalah sebagai berikut: Pertama, Pelayanan pendidikan dalam jemaat dilakukan terutama oleh mereka yang diberi karunia oleh Allah untuk mengajar (Ef.4:11). Kedua, Tujuan dari pelayanan pendidikan gereja adalah untuk mendewasakan umat Tuhan supaya mereka sanggup melayani. Kedewasaan merupakan proses membangun (Ef.4:12). Ketiga, jika pendidikan dalam jemaat dikerjakan dengan baik, hasilnya adalah kedewasaan setiap orang percaya dan suatu hubungan yang harmonis antara orang percaya secara kolektif. Proses pertumbuhan kepada kedewasaan dan kerukunan adalah proses untuk lebih menyerupai Kristus (Efs.4:13). Keempat, Pendidikan pelayanan dalam jemaat bersifat teologis sehingga dapat menghasilkan murid yang teliti dan bijaksana yang dapat mengenal kebenaran dan menghindari kesalahan karena memiliki pengetahuan (Ef.4:14). Kelima, Pelayanan pendidikan dalam jemaat yang berfungsi dengan baik, secara efektif akan menggabungkan kebenaran dengan kasih, dan bukan untuk mengorbankan salah satunya. Seorang Kristen yang dewasa akan menjadi serupa seperti Tuhannya, 'penuh anugerah dan kebenaran' (Ef. 4:15). Keenam, pelayanan pendidikan dalam jemaat yang berfungsi dengan baik tidak hanya terdiri dari beberapa guru dan banyak murid, melainkan semua unsur tersebut dapat saling membangun sebagai anak-anak Allah serta menolong satu sama lainya untuk bertumbuh secara rohani (Ef.4:16).

Jadi, dapat dikatakan bahwa pendidikan atau pengajaran yang dilakukan oleh seorang gembala sidang atau pelayan Tuhan di suatu gereja adalah untuk mendewasakan iman seluruh warga gereja, dan mereka yang sudah dewasa secara rohani ia tidak mudah untuk diombang-ambingkan oleh berbagai pengajaran-pengajaran yang menyesatkan namun jemaat semakin berakar, bertumbuh dan berbuah untuk membangun tubuh Kristus. Hal ini juga ditegaskan oleh Kurang (Kurang, 2004) yang mengatakan bahwa mengajar merupakan bagian dari pelayanan pemberian makan bagi domba yang pada hakekatnya adalah makanan rohaniah.

Korelasi pelayanan dengan gereja memiliki hubungan yang timbal balik atau sebab akibat. Karena gereja merupakan kumpulan orang percaya yang telah dipanggil dan ditebus oleh Tuhan, dan gereja mempunyai tugas dan tanggung 
jawab dalam melaksanakan Amanat Agung Yesus Kristus, maka gereja pun bertanggung jawab untuk membina, mengajar, mendidik, dan memperlengkapi warga jemaat-Nya untuk dapat terlibat di dalam pelayanan gereja. Sebab jika gereja tidak memperlengkapi jemaat-Nya untuk melayani, maka pelayanan tidak dapat berjalan dengan baik, dan gereja tidak dapat bertumbuh. Itulah sebabnya dalam suatu pelayanan gereja, Tuhan telah menetapkan para pelayanpelayan-Nya untuk sama-sama melayani.

Dan hal ini terbukti dan terlihat di tempat penelitian peneliti bahwa pengaruh pengajaran agama Kristen terhadap pelayan gereja membawa jemaat atau warga gereja untuk terlibat atau terjun di dalam pelayanan gereja, seperti: mempimpin pujian, jika disuruh berdoa sudah mau dan berani, berkhotbah atau membawa renungan singkat pada persekutuan-persekutuan doa di gereja, terlibat di dalam pelayanan diakonia mengunjungi dan mendoakan orang sakit, serta ada rasa berbagi kasih satu dengan yang lain. Inilah yang peneliti rasakan di dalamnya.

\section{Kesimpulan}

Berdasarkan hasil data penelitian dan pembahasan di atas maka peneliti memberikan suatu kesimpulan bahwa tugas seorang gembala tidak saja mengembalakan tetapi ia juga bertanggung jawab terhadap kerohanian jemaat di dalam memberikan pengajaran, pembinaan, pengarahan, dan pelatihan kepada mereka sehingga secara rohani iman mereka bertumbuh, pemahaman terhadap firman Tuhan bertumbuh, keterlibatan di dalam melayani Tuhan di gereja pun semakin berkembang karena mereka sudah diberikan ketrampilan di dalam memimpin pujian, membawa renungan firman Tuhan di dalam kelompok sel atau Penelahaan Alkitab, berkhotbah, berdoa, bahkan bersaksi atas kebaikan Tuhan di dalam kehidupannya.

\section{Rujukan}

Ahmadi, A. (1991). Ilmu Pendidikan. Jakarta: Rineka Cipta.

Akal, Y. J. (2002). Etika Pelayanan. Jakarta: Jakarta: Institut Filsafat Teologi dan Kepempinan Jaffray Jakarta.

Berkhof, L. (2008). Teologi Sistematik V: Doktrin Gereja. Surabaya: Momentum.

BibleWorks (Version 10). (n.d.).

Borrong, R. P. (2016). Melayani Makin Sungguh: Signifikansi Kode Etik Pendeta bagi Pelayanan Gereja-gereja di Indonesia. Jakarta: BPK Gunung Mulia. 
Camerling, Y. F., Lauled, M. C., \& Eunike, S. C. (2020). Gereja Bermisi Melalui Media Digital Di Era Revolusi Industri 4.0. VISIO DEI: JURNAL TEOLOGI KRISTEN, 2(1), 1-22. https:/ / doi.org/10.35909/visiodei.v2i1.68

Darmawan, I. P. A. (2019). Jadikanlah Murid: Tugas Pemuridan Gereja Menurut Matius 28:18-20. Evangelikal: Jurnal Teologi Injili dan Pembinaan Warga Jemaat, 3(2), 144-153. https:/ / doi.org/10.46445/ejti.v3i2.138

Darmawan, I. P. A., \& Kristanti, D. (2020). Penerapan Model Pembelajaran Picture and Picture dalam Pembelajaran di Sekolah Minggu. REGULA FIDEI: Jurnal Pendidikan Agama Kristen, 5(1), 1-12. https://doi.org/10.46307/rfidei.v5i1.38

Darmawan, I. P. A., \& Priskila, K. (2020). Penerapan Storytelling Dalam Menceritakan Kisah Alkitab Pada Anak Sekolah Minggu. KURIOS (Jurnal Teologi Dan Pendidikan Agama Kristen), 6(1), 35-46. https:// doi.org/10.30995/kur.v6i1.129

Dawa, M. D. L. (2020). Gembala Cendikiawan: Sebuah Gambaran Tentang Gembala Jemaat. TE DEUM: Jurnal Teologi Dan Pengembangan Pelayanan, 10, No. 1, 88 .

Hadinoto, N. K. A. (1993). Dialog dan Edukasi Keluarga Kristen dalam Masayarakat Indonesia. Jakarta: BPK Gunung Mulia.

Harmadi, M., \& Diana, R. (2020). Peran Pembinaan Warga Jemaat Dalam Menghadapi Fenomena Kekerasan Dalam Pacaran Pada Remaja. Integritas: Jurnal Teologi, 2(1), 1-10. https:/ / doi.org/10.47628/ijt.v2i1.21

Homrighausen, E. G., \& Enklaar, I. H. (1999). Pendidikan Agama Kristen. Jakarta: BPK Gunung Mulia.

Kosta, Y., \& Djadi, J. (2011). Peranan Gembala sebagai Pemimpin dalam Perspektif I Petrus 5:1-4 dan Relevansinya pada Masa Kini. Sekolah Tinggi Theologi Jaffray, 9, No. 2, 182.

Kristianto, P. L. (2006). Prinsip dan Praktek Pendidikan Agama Kristen: Penuntun bagi Mahasiswa Teoogi dan PAK, Pelayan Gereja, Guru Agama, dan Keluarga Kristen. Yogyakarta: Yayasan Andi.

Kurang, S. (2004). Dimensi Pelayanan Pastoral. Sekolah Tinggi Theologi Jaffray, 2, No. 2,5 .

Mary, E. (2020). Implikasi Ulangan 5:16 Dalam Pendidikan Keluarga. Didache: Journal of Christian Education, 1(2), 141-152. https://doi.org/10.46445/djce.v1i2.331 
Navigator, N. (1996). Memimpin Kelompok Penelaan Alkitab. Jakarta: BPK Gunung Mulia.

Nuh, S., Darmawan, I. P. A., \& Sujoko, E. (2019). Implementasi PAK Konteks Gereja Di GKII Tandang, Semarang. Jurnal Teologi Pengarah, 1(1), 59-70. https://doi.org/10.36270/pengarah.v1i1.7

Nuhamara, D. (2007). Pembimbing Pendidikan Agama Kristen. Bandung: Jurnal Info Media.

Oei, A. W. (2017). Khotbah Yang Kontekstual: Memuridkan Para Pengkhotbah Untuk Memuridkan Jemaat. SOLA GRATIA: Jurnal Teologi Biblika dan Praktika, 5(1). https:/ / doi.org/10.47596/solagratia.v5i1.53

Riniwati, R. (2020). Pembinaan Guru Sekolah Minggu Untuk Mengajarkan Konsep Keselamatan Pada Anak. Evangelikal: Jurnal Teologi Injili Dan Pembinaan Warga Jemaat, 4(2), 186-194. https://doi.org/10.46445/ ejti.v4i2.247

Ronda, D. (2016). Pemimpin dan Media: Misi Pemimpin Membawa Injil Melalui Dunia Digital. Jurnal Jaffray, 14(2), 189-198. https:/ / doi.org/10.25278/jj71.v14i2.210

Sagala, L. D. J. F. (2020). Tugas Pedagogis Gembala Dalam Menyiapkan Warga Gereja Menghadapi Perubahan Sosial. Evangelikal: Jurnal Teologi Injili Dan Pembinaan Warga Jemaat, 4(2), 167-174. https://doi.org/10.46445/ejti.v4i2.253

Salurante, T. (2021). Wawasan Dunia Kristen Sebagai Penunjuk Arah Gereja Modern Bermisi. Evangelikal: Jurnal Teologi Injili dan Pembinaan Warga Jemaat, 5(1), 16-26. https:// doi.org/10.46445/ejti.v5i1.328

Selan, R. F. (2006). Pedoman Pembinaan Warga Jemaat. Bandung: Kalam Hidup.

Sumiyati, S., \& Mendrofa, E. (2021). Implikasi Pedagogis Pada Sakramen Perjamuan Kudus Dalam Liturgi Gereja. Evangelikal: Jurnal Teologi Injili Dan Pembinaan Warga Jemaat, 5(1), 116-126. https://doi.org/10.46445/ ejti.v5i1.314

Susanti, A. (2017). Relevansi Finalitas Kristus Di Tengah-Tengah Arus Pluralisme Dan Pluralitas Masyarakat Indonesia. Evangelikal: Jurnal Teologi Injili dan Pembinaan Warga Jemaat, 1(1), 85-102. https:// doi.org/10.46445/ ejti.v1i1.65

Tafonao, T. (2018). Peran Gembala Sidang Dalam Mengajar Dan Memotivasi Untuk Melayani Terhadap Pertumbuhan Rohani Pemuda. Evangelikal: 
Jurnal Teologi Injili dan Pembinaan Warga Jemaat, 2(1). https://doi.org/10.46445/ejti.v2i1.85

Tanduklangi, R. (2020). Analisis Teologis Tentang Tujuan Pendidikan Agama Kristen (PAK) dalam Matius 28:19-20. Peada':Jurnal Pendidikan Kristen, 1 No. 1, 53. https:/ / doi.org/10.34307/ peada.v1i1.14

Tanhidy, J., Daliman, M., Suparti, H., \& Siswanto, K. (2021). Implementasi Etika Kristen Dalam Keluarga Badan Pengurus Jemaat Gereja Kemah Injil Indonesia Propinsi Jawa Tengah. Evangelikal: Jurnal Teologi Injili dan Pembinaan Warga Jemaat, 5(1), 102-115. https://doi.org/10.46445/ejti.v5i1.348

Telaumbanua, T. (2019). Peran Gembala Sidang Sebagai Pendidik Dalam Pertumbuhan Rohani Jemaat. FIDEI: Jurnal Teologi Sistematika Dan Praktika, 2, No. 2, 363.

Theissen, H. C. (2003). Teologi Sistematik. Malang: Gandum Mas.

Tomatala, Y. (2020). Gereja Yang Visioner dan Misioner di Tengah Dunia yang Berubah. Integritas: Jurnal Teologi, 2(2), 127-139. https://doi.org/10.47628/ijt.v2i2.48

Tuai, A. (2020). Strategi Pelibatan Anggota Jemaat Mewujudkan Misi Gereja yang Sehat. Integritas: Jurnal Teologi, 2(2), 188-200. https://doi.org/10.47628/ijt.v2i2.42

Widiyanto, M. A., \& Susanto, S. (2020). Pengaruh Pelayanan Kunjungan Pastoral Terhadap Pertumbuhan Rohani Jemaat. Evangelikal: Jurnal Teologi Injili Dan Pembinaan Warga Jemaat, 4(1), 39-46. https://doi.org/10.46445/ejti.v4i1.214

Zaluchu, S. E. (2020). Strategi Penelitian Kualitatif dan Kuantitatif di dalam Penelitian Agama. Evangelikal: Jurnal Teologi Injili Dan Pembinaan Warga Jemaat, 4, No. 1, 32. 